[Watkins, R. (2000). Directions for Education in the Coming Millennium: Where to From Here? New Zealand Annual Review of Education, 9, 5-22]

\section{Directions for Education in the Coming Millennium: Where to From Here?}

\section{RICHARD WATKINS}

\section{Abstract:}

Change is omnipresent and unceasing. In many ways, the circumstances that face us carry the genesis of catastrophe theory: good fortune on the one hand, and peril on the other. It is popular and prevalent to speak about the tests and opportunities arising from change, yet avoid considering the implications for the people and systems which might be most affected. But it is important to reflect on what reactions will take place when people are faced with change. The main challenge that faces us is to make sense of change, to apply the lessons we learn, to remain responsive and not be daunted.

$\mathrm{E}^{\mathrm{s}}$ ducation, or a "drawing forth", implies not so much the communication of knowledge as the discipline of the intellect, the establishment of the principles, and the regulation of the heart. As we enter a new millennium and the dawn of the e-age, ought we to ask, "Is past practice relevant to the future?" Let me suggest at least one guiding principle:

Great change demands great flexibility - the capacity to adapt quickly and continuously - to change jobs, change directions, or gain new skills. In the new global economy, the only resource that is really rooted in the nation - the ultimate source of all its wealth - is its people. To compete and win, our work-force must be well trained and highly skilled. (Reich, 1993, p. 1)

When ideas conflict in the realm of action, it is the political vocation of the scholar to reflect, weigh, and take a stand on controlling principles. Such situations give rise to the effort of academic theory, and however

\section{Richard Watkins}

unfashionable, the conflict of ideas in action is still fundamental to resolving the historical dilemmas of our time. As educators engage the emerging realities, where will they stand?

We must also consider whether we face uncertainty, ambiguity or both. Uncertainty is where we don't have needed facts to make a decision; ambiguity is where we have the facts, but are unsure what they mean, or where they might lead us.

This very much seems to embody the idea of education, and contemporary society. We certainly don't always have the facts but need to make decisions, and equally we often have the facts, but are unsure to what ends they might be employed.

\section{Predictions, Depictions, and...?}

This paper posits that human beings are naturally philosophical and inquiring. Brought face to face with the wonders of nature or the results of human endeavour, we are not generally content to observe, but feel compelled to investigate the causes through which these phenomena are produced. Being philosophical is neither haphazard nor random, but intelligent and reflective research into the realities of things.

Prediction anticipates what will happen in the future: observation notes what is happening in the present, a present that may extend from the recent past, through the immediate, to well into the future. Let us observe three things occurring at a rapid pace.

First, people are converting the contents of all the world's cultures to digital form, making the results available to any person at any place at any time.

Second, people are gaining flexible command of multiple ways to represent information, simulate interactions, and express ideas, extending the reach of intelligence, altering the spectrum of civilised achievement, and lowering thresholds to cultural participation.

Third, people are externalising diverse basic skills - to calculate, to spell, to remember, to visualise, to compare, to select - into the digital tools with which they work, making practical mastery of such skills, once an outcome of education, increasingly a given at its outset.

As these changes become evident, educators sense that the spectrum of pedagogical possibility alters appreciably. However, the escalating rate of change makes prediction no easy task. Historically, education and training systems have been built around the notion of a traditional worker, employed full-time with one employer. This is 
becoming very much an outmoded concept, which has major implications for the ways in which education is organised.

Deming recognised attempts to grapple with systems which were at the same time complex and inter-related. Further, that these systems were undergoing profound and rapid change. Systemic change, with which many in education are increasingly familiar, manifests itself in distinct ways:

- incremental change through examination and improvement of existing processes; and

- discontinuous, or large-step change, which occurs "out of the blue" and which may be a sudden change in the external environment (Deming, 1994).

The nature of such change requires more flexible approaches which recognise an end to explicit boundaries between education, training, work and retirement. These approaches must also accommodate changes in the relative distributions of those in education and/or employment, and recognise that change may well be discontinuous rather than incremental.

Already we see increased work-place learning, self-paced and computer-managed learning where students are in almost full control of their progress and assessment, and ever larger numbers of students using information technology to gain access to education and training opportunities across national boundaries at competitive costs.

Such approaches are unlikely to go away; rather they appear far more likely to increase in number, diversity, and extent, particularly with the advent of ever cheaper and accessible technology.

\section{Linear flow and technological growth}

In the past, educators relied on linear flow models for changing educational practice - largely incrementally. These make most sense in managing large-scale civil engineering projects, or the development of new or improved products for a variety of markets.

Researchers discover valuable properties or techniques; developers prepare them for the market, ensuring that they are tested and validated for performance, safety, and cost; and management allocates capital to the innovation and develops both production lines and distribution channels. This model has great simplicity and people use it to describe diverse forms of activity in technology, science, medicine, industry, government, war, and education.
Albeit simple, the model is not always sound. Historians are finding more intricate models that make sense of the way complex systems develop - systems based on discontinuities. Contemporary telecommunications did not arise via a simple linear flow from Bell's patent for the telephone. As a system, the telephone required many different people, working at different times and places through different organisations, to solve many different problems. It resulted through a distributed accomplishment by diverse people and groups who understood the technical potentials of an emergent telephone system in similar, parallel ways.

Further, the emergence of the telephone as a social system required all sorts of people to form understandings of how to integrate it in to the daily conduct of their lives. Some uses worked, others did not. Slowly, from many trials and differentiated actions, the telephone developed as a system in use, from an odd device to an ever-present resource in all aspects of life.

In deciding what to do with changing conditions, educators need to engage in the social construction of a new system, one that will come about through a diversity of innovations, by people and groups that share a common understanding of what potentialities arise in their world of practice with new technologies. This proposition may sound amorphous, but it may ultimately lead to a clear sense of what is to be done.

Let us remember, too, Aristotle's caution to seek "precision in each class of things just so far as the nature of the phenomena admits." The class of things in one particular question is the shared grasp of possibilities arising through the use of new and emerging technology. We must aim to grasp those possibilities in thought and action.

People tend to work harder to bring changes about when they expect positive results. Technology too, is cumulative - the tools and methods of one generation are used to create the technology for the next. We now have a far richer store of technological tools and processes than we have ever had to apply toward future innovations.

\section{Beware passivity}

A common response to changing conditions, whether in education or other domains, is one of passive reaction arising from a failure to perceive that new possibilities arise with changes. A classic instance of this reaction was the way in which early printers crafted books that looked exactly like illuminated manuscripts. Passive reactions attach a 
timeless necessity to arrangements that are historically contingent. Passive reaction by educators amounts to an inert effort to employ new information technologies to make the existing educational system work better, without significant changes in the structural features of that system.

Applying new technologies to current procedures, expecting them to work better but to remain essentially unchanged, does not lead to significant improvements. Rather, it forces fundamental change from within, without providing a vision of where that change should lead. In this way, educators risk being caught unawares in a cascade of unexpected innovation. We can do better by recognising that the task facing educators is to re-construct the whole system in ways that will allow it to use new communications resources and overcome the inherent, structural deficiencies of the current system.

To grasp the opportunities inherent in changing conditions, educators need to adopt an active course based on their sense of potentiality for education, but they cannot overly plan that course. Preparedness for change does not mean trying to cover all contingencies and possibilities that will only result in the paralysis of analysis. Rather it demands being open to options, making adjustments and not relying on models which have gone before as those which will survive in future.

A second, common misunderstanding lies in a compulsion to be unduly specific about the possibilities. As is implied above, reconstruction of the whole educational system is an enormously complicated process, one that will not come about by announcing a neat plan and implementing it straight away. How many times has this been tried and ended in abject, and expensive failure?

As a human experience, education remains an intensely personal process that unfolds throughout an individual's life, and an omnipresent social operation that involves billions of persons the world around.

\section{Planning and defining a future}

It is so impossibly complicated that educators cannot conceptually plan or predictably implement a re-constructed system. They can, however, shape an emerging system over time, effectively constituting key features of it through a process of social construction, if they develop a concerted sense of shared directions. Coherent historical change wells up from many different acts that move together in time, spontaneously cohering around an understanding of possibilities, at once emergent yet shared.

Educators will best define the pedagogical opportunities arising with changing conditions by concerted independent actions, by developing shared understandings and purposes, and by crafting a new common sense of where they stand and what they can do.

New information technologies are opening the system to new possibilities as surely as new building technologies did to architecture some hundred years ago. But technologies do not design new practices for us. People, acting in the face of uncertainty, must determine what they can make of emerging possibilities. Many groups and interests, pursuing many divergent inspirations, are vying for command, and a kaleidoscope of coalitions establish, through a diversity of initiatives, emerging norms of practice.

Increasingly, education will follow technology into new fields. For example, computer-based learning methods are shifting the emphasis from buildings and books towards computers and connections. Web-based information offers people greater flexibility and access. This kind of technology means that more and more learning experiences can be accessed from providers via computer technologies. So, the pressure is on institutions to look for innovative ways of helping the populace learn.

New forms of delivery make professional development for teachers an even greater priority than before. Teachers may need to practise their craft differently - for example they might be facilitators, coaches, providers of on-line user support or traditional instructors. Since teachers will be taking on more diverse roles, and because the skills they need to be teaching are constantly changing, it is essential that teachers get the professional development they need in order to be valued.

Other forces include changes in the characteristics of workers, changes in the management of work, and changes in where work is available. There is movement towards an older, more mobile workforce, in which women increasingly participate. There is also continued growth in part-time work and contract work, self-employment, and out-sourcing. There is increasing employment in service and knowledge-based industries with less emphasis on primary, manufacturing, and other resource-based industries. 


\section{Change as a Norm Rather Than an Aberration}

To effectively manage the future, and all of those things that comprise education and what it might do, we need to see change as the norm and observe that it is accelerating. It also means seeing events as inter-related. Continuing to see the world as fragmentary may no longer be as helpful as it once might have been We need to take a more holistic view.

It is as well to remember that in education we are dealing with contrasting and sometimes competing pressures and issues. Heisenberg's uncertainty principle can, and often does, apply. In essence, there are two things to recall about Heisenberg's a pproach. The first is that there is no ability to predict any behaviour or action with absolute or complete certainty. The second turns on observer intrusion, which means that the very act of observing or measuring something is likely to bring about some alteration to what is being observed or measured. The notion that the uncertainty principle applies at least as much in education as it does in quantum mechanics should surprise noone.

Increasingly, as western countries have moved to mass education systems, these systems embrace far larger numbers of notably less homogeneous people. This change has its origins in diverse sources of population increase, widening access in secondary and tertiary education, and the impact of equity and equal opportunity policies. How education and schools deal with individuals and groups who fall outside pre-conceived norms is an issue we must face.

\section{Perspectives on the future}

In assessing and addressing our individual and collective future, there may be a number of steps we might take which do not constrain, but place sensible boundaries on our otherwise unlimited imaginations.

In commentary which appeared on the Internet, Gipson Arnold wrote:

1) Don't speculate too far in advance.

2) Don't just extend current trends in a straight line, or presume the line of best fit.

3) Get as much information as possible.

4) Avoid being trapped by purist utopian wishful thinking or the chronic doomsday rantings of hopeless technophobes and conspiracy mongers.
5) Offer a variety of possible scenarios for the future instead of having only one set of predictions.

6) Create a feedback loop with the future by preparing for what you believe will happen.

7) Gain a good understanding of the nature of chaos and complex dynamic systems, and consider this knowledge when making trends.

In a truly chaotic system, patterns can be seen. These are:

- Invariants - features of life such as the 24-hour day which don't seem to ever change.

- Growth Curves - features of life such as the yearly world-wide production of cars which mimic the pattern of a life by having a rate of decline which is a mirror image of its rate of development.

- Cyclic Waves - features of life such as 56-year economic cycles which grow and decline in relation to the rhythms of nature and of life itself.

8) Apply the scientific process of subjecting your ideas to peer review.

9) Carefully apply your intuition about possible futures while considering all your data, and weigh the alternatives. (Arnold, 1997)

\section{Education for Life}

For many of us, it is difficult to conceive of a society where the processes and outcomes of education are not intrinsically related to the processes and outcomes of life itself. In very many instances, it is impractical and impossible to separate the entwined nature of education - not just schooling - and how we live on a day to day and longer term basis.

The Delors Report explains that education is at the heart of personal and community development; its mission is to enable people, without exception, to develop their talents to the full. In acknowledging tensions between the global and the local, competition and equality of opportunity and long-term and short-term considerations facing educational policy makers, the report calls for a broad concept of education that is pursued throughout life - flexible, diverse, and available at different times and in different places. 
The Report outlines four pillars of education:

- learning to know;

- learning to do;

- learning to live together, learning to live with others; and

- learning to be.

(UNESCO, 1996, pp. 20-21)

These pillars reflect the changing nature of society where there is a continuing need to upgrade and update skills throughout life.

- Learning to know encapsulates understanding the environment, living in dignity, developing occupational skills, and communicating.

- Learning to do appears to be more closely linked to vocational training; however it is by no means exclusive, and certainly captures much of higher education and elements of non-formal education.

- Learning to live together is increasingly touched on in national and international developments, and some will no doubt remember team-work, co-operation, and collaboration appearing in various competencies developed perhaps a decade ago.

- Learning to be gains recognition again in the work on civics and values education, and is implicit in much of the teaching and learning that occurs in tertiary education as well as schools.

Learning to know and learning to do, however, go well beyond traditional education and training opportunities (which have tended to focus on knowledge and skills or competencies), to include innovation and adaptation of learning to future work environments. In the rapidly changing conditions of the information age, with its emphasis on new technologies, learning to know and to do support the ability of individuals to constantly re-engage in education, and must be a force in both institutions and policy.

Changing workplaces put more importance on qualities of communication, working with others, and managing and resolving conflict. In this context, learning to live together, with its emphasis on developing co-operation, participation, and an understanding of shared or common purpose with other members of society, becomes critical. Finally these processes come together in learning to be, which acknowledges the continuing nature of personal development within the broader context of a socially cohesive society.
Skill acquisition and lifelong learning are central to the economic and social cohesion of a nation. As Colin Power, Assistant Director General - Education with UNESCO, suggested in January 1999, the greatest threat to people's security today comes from within countries, not from outside them. Thus the Delors report states (1996, p. 54):

The first point to note is the growing inequality due to rising poverty and exclusion. It is not just a question of the disparities between nations or regions in the world, but of deep divides between social groups in both developed and developing countries.

In many parts of the OECD, we are seeing a heightened awareness of the need for expanding patterns of participation in post-compulsory education and training. The growing learning revolution is based on a commitment to some form of universal entitlement, lifelong learning and economic and social cohesion. This commitment calls for the extension of education and training opportunities to a broader and more diverse population of students.

A commitment to new approaches to learning is not withoutits risks and mountains to climb. But increasingly governments are making judgements that these risks ought to be incurred and the mountains scaled.

\section{From Education for Life to a Learning Revolution}

As humanity continues to evolve, to address and re-assess the institutions and events which shape contemporary society, one lesson that should be learnt is that to continue a learning revolution, attention must be a focused on two key areas :

- the implementation issues of today, and

- the ability to look to the future and prepare for it.

As educators, though, we must be mindful of the purposes with which we are engaged and the rationales that underpin our education systems. What is argued for are approaches to education that recognise the validity, applicability, and appropriateness of different pathways, paradigms, and behaviours. Increasingly, I would also want to argue that we need to accept a diversity of approaches, each bearing its own and external legitimation if we are to tackle the complex issues before us. 
The Learning Revolution - as a way to manage education for life

A learning revolution demands innovative responses globally, nationally, and locally. Given the rate of change and the pace at which new technologies are altering the educational landscape, the learning revolution means that now more than ever, it is imperative that people work together to understand and develop viable and effective policy and practice.

While none of us can afford not to be competitive or to be complacent in the face of global shifts, there are also strong reasons why effective, responsive, and learning institutions must and will continue to be a mainstay of the provision of quality education and training in Australasia as elsewhere.

A national vision for education and training in the context of the learning revolution is to enable those responses, and in turn to be responsive. In doing so, society will be able to create an education system and institutions that others envy because they support international competitiveness, enhance social cohesion, and cater for the diversity of our peoples.

\section{Changing traditions - the classroom for example}

Traditionally, the school and the classroom have been places where teachers and students are isolated from the general culture and where information and ideas have been relatively scarce - the textbook is a meagre selection of what a field of knowledge comprises, a skilled teacher is a bundle of ignorance relative to the sum total of learning in a field, and a school library a sparse collection at best.

Networks reaching through the school into the classroom and to the desktop are ending isolation and substituting abundance for scarcity. Such a new canon is not without its pitfalls, but to cope with these we must recognise that it is a new rule, deeply different from the old. In the here and now, the educational issue changes profoundly, shifting from stratagems for disbursing scarce knowledge, to finding ways which enable people to use unlimited access to the resources of our cultures.

New media alter the ways of knowing and the opportunities for participating in the creation of knowledge. Multi-media, and its extension in virtual reality, is not merely a glitzy vehicle for edutainment hype. It is an epistemologically interesting development in our culture. For the most part, the work of thought has been located primarily in the manipulation of language, with mathematics and logic through their formal symbolisation seen as extensions of more everyday linguistic forms. Multi-media make it increasingly evident that the work of thinking can take many forms - verbal, visual, auditory, kinetic, and blends of all and each.

Of course, it is not the case that non-linguistic media are themselves new. Rather their status as serious means for creating knowledge is rising considerably. Knowledge consists primarily of cultural resources that people can store and retrieve on demand, as the need for it arises. Written, especially printed, media have long had a privileged place in education because they were easy to store and retrieve to suit the needs of users. Work in other media tended to exist in performances and monuments, which did not suit the strategies of random access.

Multi-media approaches change that condition. They subject a far wider range of communications to the full rule of random access, changing the repertoire of resources that people can store and retrieve effectively and use on demand to serve the needs of disciplined thought and enquiry. People can use digital media both to acquire ideas and to express their thoughts in these diverse ways. As a result, educators may find it increasingly difficult to favour the linguistic modality over all others and they will need to broaden the norms of academic excellence.

Digital technologies expand personal potentialities. Distributed processing and pervasive computing may or may not aggregate into artificial intelligence in the strong sense, creating a species of machines that think in a significant way. But they are clearly coming to function as a means for augmenting intelligence with respect to our human intellectual skills.

Word processors warn of anomalous spellings as they occur; spread-sheets allow anyone to perform complex calculations quickly and accurately; and data-bases permit those with good memories or bad to manage information sets that neither could handle on their own. All sorts of more specialised tools greatly lower the skill levels needed to participate effectively in wide ranges of cultural activity. Precision and exactness may become trivial proficiencies because getting it right will be easy, provided one doesn't get it wildly wrong through some accidental error.

With regard to accidental, but sometimes portentous error, the ability to estimate and guess approximate results, traditionally an educationally suspect knack, becomes an increasingly prized skill. Thus, educators sense that changes in information technologies can deeply transform the hallmarks of having acquired a decent education. Established answers to the question, "What knowledge is of most 
worth?" may not obtain under the conditions of learning and knowing that emerge with digital augmentation of human intelligence.

As educators experience changes in communications constraints, they understand that these developments open existing systems to new potentials. Individual educators may or may not welcome this state, but critic and evangelist alike sense that new conditions enable change. These, however, do not determine what will emerge: educators shape what emerges through the social construction of digital learning communities.

Around the world, observation suggests there is a remarkably consistent education system which works well for some and poorly for others. The Castor and Pollux of elitism and class bias are seemingly global, a structural feature of the educational system built over the past four centuries and perhaps longer.

Educators designed the traditional system to make optimal use of a powerful information technology - printed text. Now the means of communication available to educators are changing rapidly, and they must determine what they will accomplish with those changing conditions.

What we see now with the World Wide Web is but a hint at the fullness of cultural participation that is becoming a universal birthright. Educational policy to date has been a complicated system for allocating differential access to the cultural assets of the world's civilisations and for legitimating the results. Soon, educational policy will need to be re-defined to take into account a completely novel starting point - all the resources of the world's cultures will in principle be available to any person at any place at any time.

A movement from the pole of constraint towards its opposite will have profound effects on curricula. Traditionally, curricular resources in schools represent highly constrained choices and policies determining who teaches what to whom, and how measures assessing the resultant performances by students, teachers, and schools all serve to manage and legitimate such constraints.

Such policies result in tenaciously powerful and, some may argue, inappropriate judgments of cultural worth, as educators have rationalised a cramped canon and a sample of historical interpretations that have been simplified sometimes to the point of absurdity. In field after field, the range of cultural resources that have substantial educative worth has far exceeded what publishers could cram into textbooks or schools could purchase for their libraries. Thus, the great paradoxarose that, except at its most elite pinnacles, education has been a consistently anti-intellectual profession.

In constructing a new educational system, centring initiative and control with the student seems a fundamental principle of design and a measure of good practice. The role of teachers remains great: it is the role of fomenting questions, doubts, uncertainties; modelling strategies of inquiry; and criticizing the quality of results. In this context, curriculum design becomes the art of posing problems and facilitating work upon them. To so facilitate autonomous work by students requires great skill and sensibility. Teaching may again become a more prized and demanding profession.

The transformation of education which needs to take place is not a function of increased access to information. It is a function of increased participation in intellectual work - in advancing knowledge, in applying skill, in exercising judgment.

\section{The Impact of Change}

What social and other changes already occurring suggest is that in the next millennium:

- changes in technology and the nature of work have made it broadly more cerebral than physical;

- there is a recognisable shift in the western, industrialised economies towards occupations that require higher levels of skill and/or creativity;

- there will be an increasingly larger proportion of the population found among older persons;

- non-standard, part-time and casual employment is becoming more the norm than it has at any time in our recent history;

- despite current trends, it seems likely that in the not too distant future, all of us may have access to increased leisure or nonremunerated time; and

- work-place structures themselves are becoming flatter and less hierarchical with decreased pressure to retire and make way for others.

\section{Future challenges}

These changes may lead to a series of challenges for the future. The first is simply gaining some understanding of what the future may hold. In 
the domain of high technologies, we are increasingly faced with real or virtual innovations in areas such as those listed below:

- the new interactive, multi-media, Internet, World Wide Web, virtual reality technology stage of the information revolution;

- genetic engineering, recombinant DNA, and gene splicing;

- space exploration, industrialisation, and settlement;

- nanotechnology;

- computers, telecommunications, and robotics, which together largely comprise the first stage of the information revolution;

- rapid evolution of intermediate technologies, which are increasingly tied to sustainable development, living in harmony with nature, and voluntary simplicity;

- changes in work-place developments-including new management styles; employment and job trends; technology and work; increasing diversity; to name but a few.

Over the recent past, reforms in tertiary education have worked to try and ensure that systems, and the institutions within them, keep pace with changes in employment arrangements. The extent to which this will bear upon schools is as yet untested. If we are to continue to be successfulin building on existing reform processes, we must ensure that new forms of labour flexibility do not result in decreasing amounts of education and training or less commitment to securing Australasia's future skills base.

In an environment with rising numbers of non-traditional workers, a new mix of competencies, aligned to the domains noted above, and including those demanded in knowledge-based or service industries, will also take on increasing importance.

Given this context of change, along with the vast expansion of the electronic economy and the uncertainty as to what jobs will look like in the future, lifelong learning is central to a nation's ability to achieve a highly skilled community responsive to the needs of industry and the world of work. The future challenge which we face in education, here as in other nations, is the challenge of making education generally, including both skill acquisition and lifelonglearning, important national priorities.

To address these imperatives, we must all develop the ability to think and listen, rather than talk. Among the things which will need addressing are:
- how best to expand the view of education to embrace the many and diverse ways that people, young and old alike, will choose to engage in skill acquisition and lifelong learning;

- ways to reduce or remove the obstacles to access, participation and attainment - location, time, length and relevance of courses, physical layout, adequate facilities, and so on;

- the envisaging and building of more effective and efficient links and paths between each of the education sectors, recognising that there can no longer be a notional or actual hierarchy of school, vocational education and training, and higher education.

\section{Some Concluding Remarks}

If the agenda, sketched in the pages above, approximates the historic task of social construction required in building a new educational system enabled by digital technologies, then we see that we are at most at the beginning of this effort that spans our extended present. The technological part is the easy part. The work of educational innovation stretches before us with demanding challenges.

2000 plus: so what might we do?

- Renew the progressive contract with posterity by using new tools to pursue historically challenging goals - achieving the fulfilment of basic human rights; securing physical well-being in a sustainable global environment for all; eliminating prejudice, poverty, despair, and disease.

- Shift the central concern in cultural and education policy from limited access to open participation, displacing the long-standing politics of exclusion with a vibrant, many-sided politics of inclusion.

- Affirm the importance of independent inquiry and study as the engine of education, de-emphasising the traditional dominance of instruction.

- Re-design relationships between early childhood, school education, and higher education with an integrated intellectual environment active at all levels, engaging all as creative participants in the cultural enterprise.

- Develop a demonstration that new educational possibilities can address the intractable problems of the old system on a scale sufficient to change public expectations. 
- Create learning communities as the new milieu of practice where people meet face-to-face and via video conference, with people of mixed ages and interests engaged together in the effort of learning, supported by each other, by complete digital libraries, by open wide-area networks, and by powerful tools of analysis, synthesis, and simulation.

This extension to learning communities is a critical one. In recent years, literature on management with institutions and corporations has addressed the need for them to become learning organisations. This dictum applies no less to those working within education, or the wider society we are helping to foster and create.

Thus, education might be characterised by the same sorts of approaches spoken about by Charles Handy. A learning organisation or society is one that both learns and encourages learning in people. It creates space for people to question, think, and learn; and constantly re-frames the world and their part in it. To be effective, learning organisations and learning societies have to have formal ways of asking questions, of seeking out theories, and reflecting on them. Most importantly, members of organisations and societies - particularly those charged with research and inquiry - must be encouraged to challenge traditional ways of doing things and to suggest improvements.

It is now necessary for governments, businesses, organisations, and people to better understand change and the future, since we will all be living and working in a world that promises to be very different from the world of today. It seems axiomatic to say that when people better understand change, they also often see more opportunities for their lives and ways to help create and influence a more positive future.

In the words of Robert Reich, speaking about American renewal and higher education:

I call on you as educators and believers in the human mind, as people who understand the capacity of everyone to lead full and productive lives, believers in the power of the liberal arts to release the mind - and release the mind for life-long learning - to join with us in overcoming that gathering, enlarging gap between those who have and those who do not. Together we can do it.

It is by no means difficult to extend Reich's injunction to every one of us and into all fields of education.

\section{References}

Arnold, G. (1997). The pitfalls of prophecy. Arononet, Future Links. [Web site]

Delors, J. et al. (1996). Learning: The treasure within. Paris: UNESCO.

Deming, W. E. (1994). The new economics for industry, government, education (2nd ed.). Maryland: W. Edwards Deming Institute.

Handy, C. (1989). The age of unreason. New York: Business Books.

Heisenberg, W. (1990). Heisenberg's uncertainties and the probabilistic interpretation of wave mechanics. Amsterdam: Kluwer Academic Publishers.

Organisation for Economic Cooperation and Development. (1999). Maintaining prosperity in an aging society. Paris: OECD.

Reich, R. B. (1993, Fall). Strategies for a changing work-force. Educational Record.

Reich, R. B. (1994, Spring). American renewal and higher education. Liberal Education.

Ryback, D. (1997). Putting emotional intelligence to work: Successful leadership is more than IQ. London: Butterworth-Heinemann Publishers.

\section{The author}

Dr Richard Watkins was Director and Chief Executive of the New Zealand Council for Educational Research until June 2000. His current professional interests include educational policy, accountability, best practice and performance. He also has a long-standing interest in literacy issues. He was a key-note speaker at the 1999 AARE-NZARE conference in Melbourne, where he spoke about directions for educational research in the coming millennium. This review is drawn from that address. 